\title{
P300 asymmetry and positive symptom severity: A study in the early stage of a first episode of psychosis
}

\author{
Louis Renoult $^{\mathrm{a}, \mathrm{c}}$, Marie Prévost ${ }^{\mathrm{a}, \mathrm{c}}$, Mathieu Brodeur ${ }^{\mathrm{c}, \mathrm{d}}$, Claire Lionnet ${ }^{\mathrm{c}}$, \\ Ridha Joober ${ }^{\mathrm{b}, \mathrm{c}, \mathrm{e}}$, Ashok Malla ${ }^{\mathrm{b}, \mathrm{c}, \mathrm{e}}$, J. Bruno Debruille ${ }^{\mathrm{a}, \mathrm{b}, \mathrm{c}, *}$ \\ ${ }^{a}$ Department of Neurology and Neurosurgery, McGill University, Montréal, Québec, Canada \\ ${ }^{\mathrm{b}}$ Department of Psychiatry, McGill University, Montréal, Québec, Canada \\ ' Douglas Mental Health University Institute, Montréal, Québec, Canada \\ d Centre de Recherche en Neuropsychologie et Cognition, Université de, Montréal, Montréal, Québec, Canada \\ e Prevention and Early intervention Psychosis Program in Montreal, Canada
}

Received 12 October 2006; received in revised form 24 March 2007; accepted 28 March 2007

Available online 10 May 2007

\begin{abstract}
The amplitude of the P300 event-related potential (ERP) has been reported to be reduced over left compared to right temporal sites in schizophrenia patients. This left temporal P300 reduction has been associated with positive symptom severity and gray matter reduction in the left superior temporal gyrus. We investigated a group of patients with a first episode of schizophrenia spectrum psychosis and a group of normal controls to verify if P300 amplitude asymmetry already exists around the time of presentation for treatment. Relative to normal control subjects, no P300 asymmetry was found in patients. Nevertheless, P300 asymmetry was correlated with the severity of positive symptoms and worse global functioning (GAF), a good predictor of poor outcome.
\end{abstract}

(C) 2007 Elsevier B.V. All rights reserved.

Keywords: Schizophrenia; First-episode psychosis; P300 amplitude asymmetry; Positive symptoms

\section{Introduction}

The amplitude of the P300 event-related potential (ERP) is consistently reduced over midline electrodes, not only in schizophrenia patients (reviewed in Ford, 1999), their relatives (Bharath et al., 2000), subjects at high risk for schizophrenia (van der Stelt et al., 2005) and patients having suffered from a first-episode of

\footnotetext{
* Corresponding author. Douglas Mental Health University Institute, F. B. Common Pavilion, 6875 Boul. LaSalle, Montréal, Québec, Canada, H4H 1R3. Tel.: +1 5147616131 \#3405; fax: +1 5148884099.

E-mail address: bruno.debruille@douglas.mcgill.ca (J.B. Debruille).
}

schizophrenia (Hirayasu et al., 1998; Salisbury et al., 1998; Brown et al., 2002; McCarley et al., 2002) but also in patients with an affective psychosis (Salisbury et al., 1999; O'Donnell et al., 2004) and in several other diseases compared to normal controls (Ford, 1999).

On the other hand, a P300 amplitude asymmetry has been described in schizophrenia patients, with a greater amplitude reduction over the left than the right temporal lobe (e.g., Morstyn et al., 1983; Faux et al., 1988). In contrast with the above mentioned midline P300, this left temporal P300 abnormality has not been observed in affective psychosis patients (Salisbury et al., 1999) or in other diseases so far, and has been shown to be strongly correlated with the severity of positive symptoms 
(Shenton et al., 1989; O’Donnell et al., 1993; Debruille et al., 2005) including thought disorder (Meisenzahl et al., 2004; Kirihara et al., 2005). Interestingly, recent studies suggest that P300 asymmetry may increase with the progression of the disease. It is absent in subjects at high imminent risk for schizophrenia and is found to be more prominent in chronic than in recent-onset patients (van der Stelt et al., 2005). As well, older chronic patients (mean age 32.8 years) but not younger individuals (mean age 26.8) were found to have a reduced left temporal P300 (Iwanami et al. 2002). As to studies of patients having suffered from a first-episode of psychosis (FEP), two did report a greater reduction of $\mathrm{P} 300$ over the left than the right temporal lobe (Salisbury et al., 1998; McCarley et al., 2002), whereas others, like Hirayasu et al. (1998), did not describe this asymmetry. Interestingly, the mean age of the patients of the latter study was close to that of the younger patients of Iwanami et al. (2002), whereas, in the two FEP studies that reported P300 asymmetry (Salisbury et al., 1998; McCarley et al., 2002), mean age was clearly greater. Thus, it is possible that the asymmetry develops, or is detectable, only after having experienced symptoms of schizophrenia for a relatively longer period of time.

The objectives of the present study were thus: a) to assess if persons suffering from a first episode of previously untreated psychosis in early adulthood show evidence of temporal P300 asymmetry around the time of entry to treatment; b) to study the correlation between P300 asymmetry and the severity of positive symptoms in these patients; and c) to examine any relationship between P300 asymmetry and the duration of untreated illness/ psychosis, the quality of the premorbid adjustment and the age of the patients at the time of ERP recordings.

\section{Methods}

\subsection{Participants}

Forty four patients presenting with a first episode of a psychotic disorder (mean age: 22.6 \pm 3.6 ) for treatment to the Prevention and Early Intervention for Psychoses Program (PEPP-Montreal) signed an informed consent and were recruited for this study. The PEPP program has been designed to provide early assessment and treatment for adolescents and young adults (ages 14-30), who either have never been treated, or have received no more than one month of treatment with an antipsychotic medication. Patients' diagnosis was confirmed through administration of a Structured Clinical Interview for DSM-IV (SCID-IV) within a month of admission to the program (First et al., 1995). Based on the SCID-IV, 27 patients had a diagnosis of a schizophrenia spectrum psychosis (i.e., 19 schizophrenia, 3 schizophreniform and 5 schizoaffective disorder) and 17 patients had other psychotic disorders (4 affective psychosis, 2 delusional disorder, and 11 psychosis not otherwise specified (NOS)). Although, delusional disorder or psychosis NOS is sometimes included in schizophrenia spectrum psychosis (e.g., Franzek and Beckmann, 1998), a smaller proportion of patients in these categories maintain the same diagnosis at follow-up evaluations. Whereas, the schizophrenia spectrum diagnosis restricted to schizophrenia, schizophreniform and schizoaffective disorder has average rates of consistency of $90 \%$ (Schwartz et al., 2000; Veen et al., 2004), psychosis NOS is associated with approximately 45 to $50 \%$ consistency (Schwartz et al., 2000; Schimmelmann et al., 2005) and delusional disorder with more varying rates (e.g., about 67\% in Schwartz et al., 2000; about $87 \%$ in Schimmelmann et al., 2005). We thus decided to exclude these two last categories from our group of patients with a first episode of schizophrenia spectrum psychosis (FEP-S). Among the 27 remaining patients (mean age at the time of ERP recordings: 22 \pm 3 ), 11 were taking olanzapine (mean dose: $11.36 \mathrm{mg} \pm 7.36$ ), 6 risperidone (mean dose: $1.50 \mathrm{mg} \pm .84$ ), 2 quetiapine (mean dose: $150 \mathrm{mg} \pm 70.71), 1$ loxapine (dose: $75 \mathrm{mg}$ ) and 7 were not medicated at the time of ERP recordings. All were right-handed. Scores on Global Assessment of Functioning (GAF) were obtained based on ratings conducted at the time of the first assessment. Patients were administered a semi-structured interview schedule, the Circumstances of Onset and Relapse Schedule (Norman et al., 2004; Malla et al., 2006), to provide estimates of the time of onset of psychosis, of the duration of untreated psychosis (DUP) and of the duration of untreated illness (DUI). DUP was defined as the period between the time of onset of psychotic symptoms and the commencement of adequate treatment (taking anti-psychotic medication for a period of one month or until significant response, which ever came first). DUI corresponded to the length of time between the onset of any psychiatric symptoms and the initiation of antipsychotic therapy. Based on 20 randomly selected cases of FEP in our program, a relatively high degree of agreement was achieved on estimation of DUP between three raters (ICC ranging from .86 to .98). Pre-morbid adjustment was assessed with the Pre-morbid Adjustment Scale (PAS; Cannon-Spoor et al., 1982). It included 2 sections: the PAS-1 for childhood (5 to1 1 years of age) and the PAS-2 for early adolescence (12 to 15 ).

A group of healthy right-handed subjects $(n=14)$ matched for mean age (24 years \pm 4$)$ and gender (11 males/3 females) was also recruited. Control subjects had 
a phone interview with an experienced research assistant in which they were asked if themselves or one of their first degree relatives ever had a psychological problem. They were also asked whether they were previously hospitalized and whether they had already taken medication for psychiatric reasons. Finally, the presence of any history of head injury with loss of consciousness longer than $5 \mathrm{~min}$, or of epilepsy crises was inquired. Subjects answering positively to one of these questions were excluded. It was also possible to exclude all potential participants who were using illegal drugs except for a few cannabis users but all participants agreed not to take cannabis or alcohol the day before or the day of the recording. All subjects signed an informed consent form accepted by the Douglas hospital research ethics board.

\subsection{Symptom evaluation}

Patients were evaluated with the Scale for the Assessment of Positive Symptoms (SAPS) (Andreasen, 1984) and the Scale for the Assessment of Negative Symptoms (SANS) (Andreasen, 1983). Total scores (SAPT) were computed for positive symptoms. Scores were obtained for reality distortion (RDT) by adding respective scores for items of the hallucination and delusion sub-scales, and for disorganization (DZT) by adding the scores for positive formal thought disorder and bizarre behavior of the SAPS and inappropriate affect item of the SANS (Andreasen et al., 1995) (Table 1).

\subsection{Oddball task}

All subjects performed an auditory oddball task. Target and non-target stimuli were delivered randomly. The target was a $2000 \mathrm{~Hz}$ tone presented $20 \%$ of the trials. The non-target was a $1000 \mathrm{~Hz}$ tone presented $80 \%$ of the trials. Both tones were delivered binaurally at a $70 \mathrm{~dB}$ sound pressure level for $100 \mathrm{~ms}$ with a rise/fall time of $10 \mathrm{~ms}$. Adjacent stimuli were separated by a $1440 \mathrm{~ms}$ interstimulus time. There were 4 blocks containing 150 stimuli each and separated by 5 min intervals. In each block, subjects had to mentally count the number of times the target tone was presented and to keep their eyes open (Debruille et al., 2005). After each block, subjects were asked how many stimuli they had counted. Target count accuracy was computed as the difference between the correct number and the number each subject gave.

\subsection{ERP recordings}

All patients were recorded at an interval less than, or equal to, 2 weeks from their clinical evaluation. Scalp
Table 1

Demographic and clinical variables for all subjects

\begin{tabular}{llllll}
\hline & \multicolumn{2}{l}{ FEP-S $(n=27)$} & & \multicolumn{2}{l}{ Ctrl $(n=14)$} \\
\cline { 2 - 3 } & $\begin{array}{l}\text { Mean } \\
(\text { SD })\end{array}$ & $\begin{array}{l}\text { Median } \\
(\text { range })\end{array}$ & & $\begin{array}{l}\text { Mean } \\
(S D)\end{array}$ & $\begin{array}{l}\text { Median } \\
(\text { range })\end{array}$ \\
\hline Age & $22( \pm 3)$ & $22(17-28)$ & & $24( \pm 4)$ & $25(18-30)$ \\
Gender & $21 \mathrm{~m} / 6 \mathrm{f}$ & & & $11 \mathrm{~m} / 3 \mathrm{f}$ & \\
Medication & $172( \pm 181)$ & $125(0-750)$ & - & - \\
DUP & $32( \pm 39)$ & $16(1-152)$ & - & - \\
DUI & $190( \pm 217)$ & $120(15-898)$ & - & - \\
PAS 1 & $.2( \pm .1)$ & $.1(0-.4)$ & - & - \\
PAS 2 & $.3( \pm .1)$ & $.3(.1-.4)$ & - & - \\
GAF & $41( \pm 9)$ & $42(24-58)$ & - & - \\
SAPT & $20( \pm 17)$ & $16(0-53)$ & & - \\
RDT & $14( \pm 12)$ & $11(0-39)$ & - & - \\
DZT & $6( \pm 7)$ & $5(0-26)$ & - & - \\
\hline
\end{tabular}

Acronym meanings: FEP-S: patients suffering from a first episode of a schizophrenia spectrum psychosis. Ctrl: control subjects. Medication: medication dose in chlorpromazine equivalents (for more details see Methods section); DUP: duration of untreated psychosis in weeks; DUI: duration of untreated illness in weeks; PAS: quality of the premorbid adjustment, PAS 1: during childhood (5-11), PAS 2: during early adolescence (age 12-15), values of PAS range from 0 to 1 , with 0 representing the best premorbid adjustment; GAF: Global Assessment of Functioning; SAPT: Total score for positive symptoms; RDT: Total score for reality distortion; DZT: Total score for disorganization.

encephalogram (EEG) was recorded at 5 electrode sites $(\mathrm{Fz}, \mathrm{Pz}, \mathrm{Cz}, \mathrm{T} 3$ and $\mathrm{T} 4$ ) placed according to the international expanded 10-20 system (Electrode nomenclature committee, 1991), using the right earlobe as a reference. Eye movements and blinks were controlled by F7 and F8 for horizontal movements and by FP2 and an additional electrode placed on the right cheek for vertical movements. The impedance of the electrodes was kept below $5 \mathrm{k} \Omega$. The EEG was amplified 20,000 times by Contact Precision amplifiers. High- and low-pass filter half-amplitude cut-offs were set at .01 and $100 \mathrm{~Hz}$, with an additional $60 \mathrm{~Hz}$ electronic notch filter. Signals were digitized on-line at a sampling rate of $256 \mathrm{~Hz}$ and stored along with stimulus and response codes for subsequent averaging using the Instep (version 4.3) software package. EEG epochs contaminated by eyes movements, excessive myogram, amplifier saturations or analog to digital clipping were removed offline with automatic rejection criteria: trials for which analog to digital clipping exceeded $100 \mathrm{~ms}$, and electrodes for which amplitude exceeded $\pm 100 \mu \mathrm{V}$ were excluded from averaging.

Target ERPs were computed by averaging $1000 \mathrm{~ms}$ epochs for each electrode starting $200 \mathrm{~ms}$ before the onset of the stimulus. The latency of the peak of the positive deflection occurring between 200 and $500 \mathrm{~ms}$ was determined for each group grand average. For all 
recording sites $(\mathrm{Fz}, \mathrm{Pz}, \mathrm{Cz}, \mathrm{T} 3$ and $\mathrm{T} 4)$ and in both groups, P300 peaked between 300 and $400 \mathrm{~ms}$. More precisely, the electrode site at which the P300 had the earliest maximum was $\mathrm{Cz}(312 \mathrm{~ms}$ for FEP-S and 331 for the controls), while the latest maximum was found on T3 (370 ms for FEP-S and 366 for the controls) for both groups. Therefore, mean P300 voltage amplitudes were computed in a 300 to $400 \mathrm{~ms}$ time window relative to the -200 to $0 \mathrm{~ms}$ baseline.

Meanwhile, the latencies of the P300s were measured in each subject by assessing the times of the maximum of the positive peak observed between 200 and $500 \mathrm{~ms}$. This was done after smoothing the curves so that only 1 positive peak appeared in the 200-500 window.

\subsection{Data analyses}

Three mixed-model repeated-measure ANOVAs were used with group (controls vs. FEP patients) as the between subject factor. For the study of P300 latency, the electrode factor was used as within subject factor. It had five levels, frontal $(\mathrm{Fz})$, central $(\mathrm{Cz})$, parietal $(\mathrm{Pz})$, left (T3) and right mid-temporal (T4). For the study of P300 amplitude, one ANOVA was run with anterior-posterior site ( $\mathrm{Fz}$ vs. $\mathrm{Cz}$ vs. $\mathrm{Pz}$ ) as within subject factor to investigate midline P300 amplitude, and the other ANOVA with laterality (T3 vs. T4) to investigate P300 asymmetry. To avoid confounding effects that could be generated by global between group differences as to their P300 amplitudes, all lateral analyses were conducted on normalized mean amplitudes, that is by dividing amplitudes at $\mathrm{T} 3$ and at $\mathrm{T} 4$ by the mean amplitude observed at Cz, as in Salisbury et al. (1998).

Pearson's correlations $(r)$ were calculated in patients between clinical variables and the mean amplitude of P300 at the left temporal site (T3), and between clinical variables and P300 asymmetry, as measured by the subtraction of the amplitude of the P300 at the left temporal site from the amplitude of the $\mathrm{P} 300$ at the right temporal site (T4-T3).

For the figures, the ERP waveforms were smoothed to remove high frequency noise. This was done by simple averaging of groups of 3 consecutive points 5 times using the Instep software package (version 4.3).

\section{Results}

\subsection{Target count accuracy}

The FEP group performed less well (mean accuracy rate $95 \%$ ) than the control group (98\%) but this difference was not significant $[F(1,39)=1.75, p=.19]$.

\subsection{P300 latency}

The ANOVA on P300 latency revealed no betweengroup difference in P300 latency $[F(1,39)=.11$, $p=.92]$, nor any interaction between group and electrodes $[F(4,156)=.53, p=.66]$ (see Fig. 1$)$.

\subsection{Midline P300 amplitude}

Mean P300 amplitudes were maximal at Pz for both groups ( $10.08 \mu \mathrm{V} \pm 3.36$ in controls; $5.66 \mu \mathrm{V} \pm 2.48$ in FEP patients). The ANOVA performed with midline site measures showed that P300 amplitudes were generally greater in the control group than in the FEP group $[F(1,39)=23.8, p<.001]$ (see Fig. 1). The group difference was significantly larger at $\mathrm{Cz}$ than at other electrode sites $[F(2,78)=13.63, p \ll .001]$. Post-hoc analysis for each electrode site revealed that P300

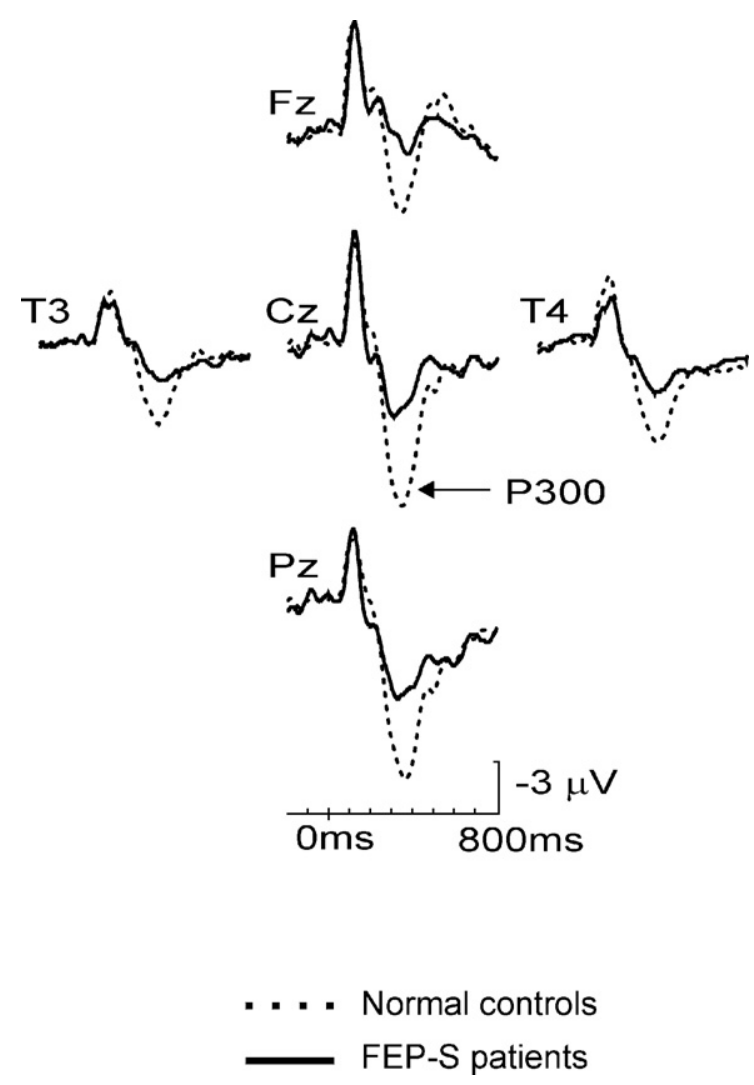

Fig. 1. Grand average of the target event-related potentials (ERPs) for each group. Solid lines are for patients with a first episode of schizophrenia spectrum psychosis (FEP-S). Dashed lines are for normal controls. All subjects performed an auditory oddball task. Target and non-target stimuli were delivered randomly. The target was a $2000 \mathrm{~Hz}$ tone presented $20 \%$ of the trials. The non-target was a $1000 \mathrm{~Hz}$ tone presented $80 \%$ of the trials. 
Table 2

Pearson correlation $(r)$ between mean amplitude of the P300 at the left temporal site (T3) and clinical variables, and between P300 asymmetry (T4-T3) and the same variables in FEP-S patients

\begin{tabular}{lccccc}
\hline & $\mathrm{T} 3$ & & \multicolumn{2}{c}{$\mathrm{T} 4-\mathrm{T} 3$} \\
\cline { 2 - 3 } \cline { 5 - 6 } & $r$ & $p$ & & $r$ & $p$ \\
\hline Age & -.13 & .52 & & +.03 & .86 \\
Sex & +.03 & .88 & & +.05 & .80 \\
Medication & -.26 & .20 & -.06 & .78 \\
DUP & -.15 & .48 & +.32 & $\mathbf{. 0 7}$ \\
DUI & -.20 & .35 & +.18 & .39 \\
PAS 1 & +.03 & .88 & +.11 & .62 \\
PAS 2 & -.11 & .60 & +.16 & .45 \\
GAF & +.15 & .23 & -.33 & .04 \\
SAPT & -.01 & .48 & +.47 & $\mathbf{. 0 1}$ \\
RDT & -.09 & .31 & +.40 & $\mathbf{. 0 2}$ \\
DZT & -.15 & .23 & +.44 & $\mathbf{. 0 1}$ \\
\hline
\end{tabular}

$p$ values are given for one-tailed tests of significance for positive symptoms scores and GAF for which there were a priori hypotheses. Two-tailed tests of significance were used for all other variables. T3: Mean amplitude of the P300 at left temporal site. T4-T3: Subtraction of the mean amplitude of the P300 at the left temporal site (T3) from the mean amplitude of the P300 at the right temporal site (T4). Sex: $1=$ male; 2 =female. See Table 1 legend for all other demographic and clinical variables' acronyms.

amplitudes were significantly greater in controls than in FEP-S at $\mathrm{Fz}[F(1,40)=12.87, p=.001], \mathrm{Cz}[F(1,40)=$ $25.36, p \ll .001]$ and $\mathrm{Pz}[F(1,40)=25.27, p \ll .001]$.

\subsection{Asymmetry in P300 amplitude over temporal sites (T3 and T4)}

Mean normalized T4-T3 amplitude differences were $.13( \pm .21)$ in control subjects and $.19( \pm .58)$ in FEP patients. The ANOVA performed with lateral site measures did not reveal any significant interaction between laterality and group $[F(1,39)=.16, p=.69]$, showing that $\mathrm{P} 300$ was not at all more asymmetrical in the patients' groups than in the control group. ${ }^{1}$

There was no significant correlation between P300 asymmetry and age, sex, medication dose, DUI or PAS in the patients' group (Table 2). However P300

\footnotetext{
${ }^{1}$ Because the activity of the reference site is eliminated by the subtraction, the exact placement of the reference site has no importance for such analysis (Hagemann et al., 2001). The same analysis with ERPs obtained with an averaged reference instead of a right earlobe reference was also associated with an absence of interaction between laterality and group: $[F(1,39)=.75, p=.39]$. The similarity between the two analyses is further illustrated by the fact that when voltage amplitudes obtained with an average reference were normalized with the original $\mathrm{Cz}$ values (right earlobe reference) instead of their respective $\mathrm{Cz}$ values, the statistical results of the ANOVA were identical: $[F(1,39)=.16, p=.69]$.
}

asymmetry was negatively correlated with global assessment of functioning score (GAF), and positively correlated with the total scores of positive symptoms (SAPT, RDT, and DZT). Moreover, there was a trend for more asymmetric patients to have a longer duration of untreated psychosis (DUP) (see Table 2).

\subsection{Left temporal P300 amplitude (T3)}

There was no significant correlation between the amplitude of the P300 at the left temporal site and age, sex, medication dose, DUP, DUI, PAS, global assessment of functioning (GAF) or symptoms' scores in FEP patients (see Table 2).

\section{Discussion}

The present study confirmed a general decrease in midline P300 amplitude in patients with a first episode of schizophrenia spectrum psychosis (FEP-S) relative to normal controls. However, no P300 asymmetry was found, nor was there any correlation observed between left temporal P300 amplitude and severity of symptoms. Nevertheless, higher levels of positive symptoms were associated with greater P300 asymmetry (the subtraction of the amplitude of the P300 at the left temporal site from the amplitude of the $\mathrm{P} 300$ at the right temporal site). Moreover, greater P300 asymmetry was associated with worse global functioning scores (GAF) and showed a tendency to be associated with longer DUP.

The substantial reduction in midline P300 amplitude in FEP-S patients relative to normal controls confirms previous findings (e.g., Salisbury et al. 1998; McCarley et al. 2002). However, this reduction appears to be of greater magnitude in the present study: P300 peak amplitudes in FEP-S patients were about half of that found by Salisbury et al. (1998), and one third of that found by McCarley et al. (2002). In addition to the differences between the experimental protocols used, a possible explanation for this discrepancy is medication. In Salisbury et al. (1998) and in McCarley et al. (2002), patients were more medicated, with mean chlorpromazine equivalent doses of 239.6 and $262.7 \mathrm{mg}$ respectively compared to $172 \mathrm{mg}$ in the present study. Moreover, FEPS patients in McCarley et al. (2002) had been medicated for a longer time (158.9 days on average) before admission, while the criteria for inclusion in the present study was antipsychotic medication of no more than 30 days duration. Although general amplitude reduction has been shown to be present in non-medicated firstepisode patients (Hirayasu et al., 1998; Demiralp et al., 2002), P300 amplitude may be substantially increased by 
medication (Coburn et al., 1998; Demiralp et al., 2002; Gonul et al., 2003; Wang et al., 2005). Differences in treatment could thus account for the larger P300 amplitudes observed in the aforementioned studies compared to the present study.

We failed to observe a greater P300 asymmetry over temporal sites in FEP-S patients compared to control subjects. This absence of significant asymmetry difference cannot be explained by the importance of the general amplitude reduction in patients as several studies have demonstrated that general low P300 amplitudes were associated with more asymmetry (Strik et al., 1994; Hill and Weisbrod, 1999; Iwanami et al., 2002). Meanwhile, we found that P300 amplitude asymmetry was positively correlated with the severity of positive symptoms. Moreover, asymmetry was negatively correlated with global functioning score (GAF) and showed a trend to be positively correlated with longer duration of untreated psychosis (DUP). These results are consistent with the anatomical substrates assumed to be involved in the temporal P300. Indeed, greater volume reduction of the temporal gray matter has been found in patients having more severe clinical symptoms and in those with longer DUPs (Barta et al., 1990; Shenton et al., 1992; and for DUPs: Lappin et al., 2006). P300 asymmetry may thus be present only in subgroups of patients, having more severe clinical symptoms and possibly suffering from related reduction in gray matter (Ford et al., 2000). However, the relatively small sample size and limited variance in DUP may have led to insufficient power to detect significant correlations between P300 asymmetry and DUP.

Alternatively, our findings of an absence of greater P300 asymmetry relative to normal controls in a group of young FEP-S patients with globally short DUPs (the median DUP was 16 weeks in these patients) may be taken with other data to suggest that left temporal P300 deficits in schizophrenia would be progressive. Indeed, these deficits are absent in subjects at high imminent risk for schizophrenia and are found to be more prominent in chronic than in recent-onset patients (van der Stelt et al., 2005). P300 asymmetry may thus appear after what is referred to as a 'critical period' in the course of schizophrenia, that is approximately the first 3 years following onset of the first episode where psychological and biological plasticity are maximum (Birchwood et al., 1998).

While the delay after the onset of the first symptoms could thus be of critical importance, patients' age at the time of the assessment could also be relevant (Iwanami et al., 2002). The superior temporal gyrus (STG), to which P300 has been associated (e.g., Knight et al., 1989), is one of the last brain regions to mature. Indeed, the physiological decrease in gray matter in this area seems to start close to 20 years of age in normal subjects (Lenroot and Giedd, 2006; Giedd et al., 1999). It is possible that a left-sided increase in gray matter loss would begin during this same period in schizophrenia. A recent MRI study in young offspring of patients with schizophrenia (mean age: 14.9 years) did not find a left sided asymmetry in the STG, even if general gray matter decrease was observed in these subjects at risk for schizophrenia compared to normal controls (Rajarethinam et al., 2004). Although gray matter reduction was shown to be progressive in the left STG in FEP patients (Kasai et al., 2003), no study to our knowledge investigated groups of patients with mean ages less than 25 years. Accordingly, the young age of our patients by itself could explain why no P300 asymmetry was found in the present study whereas it was reported along with a left STG volume reduction in 2 other studies (Salisbury et al. 1998; McCarley et al. 2002).

In conclusion, despite the absence of a greater P300 asymmetry in patients with a first episode of schizophrenia spectrum psychosis than in normal controls, we observed a positive correlation between the magnitude of this asymmetry and positive symptom severity. Also, P300 asymmetry was correlated with worse global functioning, a good predictor of poor outcome. Longitudinal studies of patients in the early stages of their illness would be helpful to track the progress of the asymmetry in individual cases and test if it is a good predictor of the outcome.

\section{References}

Andreasen, N.C., 1983. Scale for the Assessment of Negative Symptoms (SANS). University of Iowa, Iowa City, IA.

Andreasen, N.C., 1984. The Scale for the Assessment of Positive Symptoms (SAPS). University of Iowa, Iowa City, IA.

Andreasen, N.C., Arndt, S., Alliger, R., Miller, D., Flaum, M., 1995. Symptoms of schizophrenia. Methods, meanings, and mechanisms. Arch. Gen. Psychiatry 52, 341-351.

Barta, P.E., Pearlson, G.D., Powers, R.E., Richards, S.S., Tune, L.E., 1990. Auditory hallucinations and smaller superior temporal gyral volume in schizophrenia. Am. J. Psychiatry 147, 1457-1462.

Bharath, S., Gangadhar, B.N., Janakiramaiah, N., 2000. P300 in family studies of schizophrenia: review and critique. Int. J. Psychophysiol. 38, 43-54.

Birchwood, M., Todd, P., Jackson, C., 1998. Early intervention in psychosis: the critical-period hypothesis. Br. J. Psychiatr., Suppl. 172, 53-59.

Brown, K.J., Gonsalvez, C.J., Harris, A.W., Williams, L.M., Gordon, E., 2002. Target and non-target ERP disturbances in first episode vs. chronic schizophrenia. Clin. Neurophysiol. 113, 1754-1763.

Cannon-Spoor, H.E., Potkin, S.G., Wyatt, R.J., 1982. Measurement of premorbid adjustment in chronic schizophrenia. Schizophr. Bull. 8, 470-484.

Coburn, K.L., Shillcutt, S.D., Tucker, K.A., Estes, K.M., Brin, F.B., Merai, P., Moore, N.C., 1998. P300 delay and attenuation in 
schizophrenia: reversal by neuroleptic medication. Biol. Psychiatry 44, 466-474.

Debruille, J.B., Schneider-Schmid, A., Dann, P., King, S., Laporta, M., Bicu, M., 2005. The correlation between positive symptoms and left temporal event-related potentials in the P300 time window is auditory specific and training sensitive. Schizophr. Res. 78, $117-125$

Demiralp, T., Ucok, A., Devrim, M., Isoglu-Alkac, U., Tecer, A., Polich, J., 2002. N2 and P3 components of event-related potential in first-episode schizophrenic patients: scalp topography, medication, and latency effects. Psychiatry Res. 111, 167-179.

Electrode nomenclature committee, 1991. Modified expanded 10-20 system. American EEG society. J. Clin. Neurophysiol. 35, 200-202.

Faux, S.F., Torello, M.W., McCarley, R.W., Shenton, M.E., Duffy, F.H., 1988. P300 in schizophrenia: confirmation and statistical validation of temporal region deficit in P300 topography. Biol. Psychiatry. 23, 776-790

First, M.B., Spitzer, R.L., Gibbon, M., Williams, J.B.W., 1995. Structured Clinical Interview for the DSM-IV Axis I Disorders (SCID). New York State Psychiatric Institute, Biometrics Research: New York.

Ford, J.M., 1999. Schizophrenia: the broken P300 and beyond. Psychophysiology 36, 667-682.

Ford, J.M., Mathalon, D.H., White, P.M., Pfefferbaum, A., 2000. Left temporal deficit of P300 in patients with schizophrenia: effects of task. Int. J. Psychophysiol. 38, 71-79.

Franzek, E., Beckmann, H., 1998. Different genetic background of schizophrenia spectrum psychoses: a twin study. Am. J. Psychiatry 155 (1), 76-83.

Giedd, J.N., Blumenthal, J., Jeffries, N.O., Castellanos, F.X., Liu, H., Zijdenbos, A., Paus, T., Evans, A.C., Rapoport, J.L., 1999. Brain development during childhood and adolescence: a longitudinal MRI study. Nat. Neurosci. 2 (10), 861-863.

Gonul, A.S., Suer, C., Coburn, K., Ozesmi, C., Oguz, A., Yilmaz, A., 2003. Effects of olanzapine on auditory P300 in schizophrenia. Prog. Neuro-Psychopharmacol. Biol. Psychiatry 27, 173-177.

Hagemann, D., Naumann, E., Thayer, J.F., 2001. The quest for the EEG reference revisited: a glance from brain asymmetry research. Psychophysiology 38 (5), 847-857.

Hill, H., Weisbrod, M., 1999. The relation between asymmetry and amplitude of the P300 field in schizophrenia. Clin. Neurophysiol. $110,1611-1617$.

Hirayasu, Y., Asato, N., Ohta, H., Hokama, H., Arakaki, H., Ogura, C., 1998. Abnormalities of auditory event-related potentials in schizophrenia prior to treatment. Biol. Psychiatry 43, 244-253.

Iwanami, A., Kato, N., Kasai, K., Kamio, S., Furukawa, S., Fukuda, M., Nakagome, K., Araki, T., Okajima, Y., Isono, H., Kamijima, K., 2002. P300 amplitude over temporal regions in schizophrenia. Eur. Arch. Psychiatry Clin. Neurosci. 252, 1-7.

Kasai, K., Shenton, M.E., Salisbury, D.F., Hirayasu, Y., Lee, C.U., Ciszewski, A.A., Yurgelun-Todd, D., Kikinis, R., Jolesz, F.A., McCarley, R.W., 2003. Progressive decrease of left superior temporal gyrus gray matter volume in patients with first-episode schizophrenia. Am. J. Psychiatry 160, 156-164.

Kirihara, K., Araki, T., Kasai, K., Maeda, K., Hata, A., Uetsuki, M., Yamasue, H., Rogers, M.A., Kato, N., Iwanami, A., 2005. Confirmation of a relationship between reduced auditory P300 amplitude and thought disorder in schizophrenia. Schizophr. Res. 80, 197-201.

Knight, R.T., Scabini, D., Woods, D.L., Clayworth, C.C., 1989. Contributions of temporal-parietal junction to the human auditory P3. Brain Res. 502, 109-116.
Lappin, J.M., Morgan, K., Morgan, C., Hutchison, G., Chitnis, X., Suckling, J., Fearon, P., McGuire, P.K., Jones, P.B., Leff, J., Murray, R.M., Dazzan, P., 2006. Gray matter abnormalities associated with duration of untreated psychosis. Schizophr. Res. 83, 145-153.

Lenroot, R.K., Giedd, J.N., 2006. Brain development in children and adolescents: insights from anatomical magnetic resonance imaging. Neurosci. Biobehav. Rev. 30, 718-729.

Malla, A., Norman, R., Schmitz, N., Manchanda, R., Bechard-Evans, L., Takhar, J., Haricharan, R., 2006. Predictors of rate and time to remission in first-episode psychosis: a two-year outcome study. Psychol. Med. 36, 649-658.

McCarley, R.W., Salisbury, D.F., Hirayasu, Y., Yurgelun-Todd, D.A., Tohen, M., Zarate, C., Kikinis, R., Jolesz, F.A., Shenton, M.E., 2002. Association between smaller left posterior superior temporal gyrus volume on magnetic resonance imaging and smaller left temporal P300 amplitude in first-episode schizophrenia. Arch. Gen. Psychiatry 59, 321-331.

Meisenzahl, E.M., Frodl, T., Muller, D., Schmitt, G., Gallinat, J., Zetsche, T., Marcuse, A., Juckel, G., Leinsinger, G., Hahn, K., Moller, H.J., Hegerl, U., 2004. Superior temporal gyrus and P300 in schizophrenia: a combined ERP/structural magnetic resonance imaging investigation. J. Psychiat. Res. 38, 153-162.

Morstyn, R., Duffy, F., McCarley, R.W., 1983. Altered P300 topography in schizophrenia. Arch. Gen. Psychiatry 40, 729-734.

Norman, R.M., Malla, A.K., Verdi, M.B., Hassall, L.D., Fazekas, C., 2004. Understanding delay in treatment for first-episode psychosis. Psychol. Med. 34, 255-266.

O’Donnell, B.F., Shenton, M.E., McCarley, R.W., Faux, S.F., Smith, R.S., Salisbury, F., Nestor, P.G., Pollak, S.D., Kikinis, R., Jolesz, F.A., 1993. The auditory N2 component in schizophrenia: relationship to MRI temporal lobe gray matter and to other ERP abnormalities. Biol. Psychiatry 34, 26-40.

O’Donnell, B.F., Vohs, J.L., Hetrick, W.P., Carroll, C.A., Shekhar, A., 2004. Auditory event-related potential abnormalities in bipolar disorder and schizophrenia. Int. J. Psychophysiol. 53, 45-55.

Rajarethinam, R., Sahni, S., Rosenberg, D.R., Keshavan, M.S., 2004. Reduced superior temporal gyrus volume in young offspring of patients with schizophrenia. Am. J. Psychiatry 161, 1121-1124.

Salisbury, D.F., Shenton, M.E., Sherwood, A.R., Fischer, I.A., Yurgelun-Todd, D.A., Tohen, M., McCarley, R.W., 1998. Firstepisode schizophrenic psychosis differs from first episode affective psychosis and controls in P300 amplitude over left temporal lobe. Arch. Gen. Psychiatry 55, 173-180.

Salisbury, D.F., Shenton, M.E., McCarley, R.W., 1999. P300 topography differs in schizophrenia and manic psychosis. Biol. Psychiatry 45, 98-106.

Schimmelmann, B.G., Conus, P., Edwards, J., McGorry, P.D., Lambert, M., 2005. Diagnostic stability 18 months after treatment initiation for first-episode psychosis. J. Clin. Psychiatry 66, 1239-1246.

Schwartz, J.E., Fennig, S., Tanenberg-Karant, M., Carlson, G., Craig, T., Galambos, N., Lavelle, J., Bromet, E.J., 2000. Congruence of diagnoses 2 years after a first-admission diagnosis of psychosis. Arch. Gen. Psychiatry. 57, 593-600.

Shenton, M.E., Faux, S.F., McCarley, R.W., Ballinger, R., Coleman, M., Torello, M., Duffy, F.H., 1989. Correlations between abnormal auditory P300 topography and positive symptoms in schizophrenia: a preliminary report. Biol. Psychiatry 25, 710-716.

Shenton, M.E., Kikinis, R., Jolesz, F.A., Pollak, S.D., LeMay, M., Wible, C.G., Hokama, H., Martin, J., Metcalf, D., Coleman, M., 1992. Abnormalities of the left temporal lobe and thought disorder 
in schizophrenia. A quantitative magnetic resonance imaging study. N. Engl. J. Med. 327, 604-612.

Strik, W.K., Dierks, T., Franzek, E., Stober, G., Maurer, K., 1994. P300 in schizophrenia: interactions between amplitudes and topography. Biol. Psychiatry $35,850-856$.

van der Stelt, O., Lieberman, J.A., Belger, A., 2005. Auditory P300 in high-risk, recent-onset and chronic schizophrenia. Schizophr. Res. 77, 309-320.
Veen, N.D., Selten, J.P., Schols, D., Laan, W., Hoek, H.W., van der Tweel, I., Kahn, R.S., 2004. Diagnostic stability in a Dutch psychosis incidence cohort. Br. J. Psychiatry 185, 460-464.

Wang, J., Hirayasu, Y., Hokama, H., Tanaka, S., Kondo, T., Zhang, M., Xiao, Z., 2005. Influence of duration of untreated psychosis on auditory P300 in drug-naive and first-episode schizophrenia. Psychiatry Clin. Neurosci. 59, 209-214. 